\title{
IPTEKS SISTEM PELAPORAN AKUNTANSI BANK INDONESIA
}

\author{
Preisia Sigar ${ }^{1}$, Sintje Rondonuwu $^{2}$ \\ ${ }^{1,2}$ Jurusan Akuntansi, Fakultas Ekonomi dan Bisnis Unsrat, Jl. Kampus Unsrat, Manado, 95115, Indonesia \\ E-mail : preisiachiasigar@gmail.com
}

\begin{abstract}
Bank Indonesia is the Central Bank. The Central Bank is the center of monetary policy and monetary stability in Indonesia. As a Central Bank certainly has a system in accounting reporting. Based on research conducted at BI and existing discussions, the conclusion that can be taken is that BI adheres to the system issued by the Bank Indonesia Accounting Policy (KAKBI) based on the Bank Indonesia Governor Regulation (PDGBI). Suggestion that BI continues to improve transparency and accountability so that the quality of bank Indonesia reporting system information is accurate and reliable.
\end{abstract}

Keywords: accounting system, repportimg

\section{PENDAHULUAN}

Setiap pengambilan keputusan ekonomi tentu memerlukan informasi keuangan yang akurat agar keputusan yang diambil tepat dan berhasil yang sesuai dengan kaidah-kaidah yang ada. Dalam setiap Perusahaan tentunya mempunyai standar atau sistem dalam Akuntansi. Agar akuntansi dapat menghasilkan informasi keuangan atau yang lebih kita kenal dengan nama laporan keuangan sesuai dengan yang diharapkan, maka perlu didukung oleh suatu sistem akuntansi yang baik dan andal.

Bank Indonesia mempunyai standar akuntansi tersendiri yaitu Kebijakan Akuntansi Keuangan Bank Indonesia (KAKBI). Kebijakan Akuntansi peraturan dan prinsip-prinsip yang harus diterpakan oleh setiap Entitas. Oleh karena itu karena Bank Indonesia adalah institusi publik yang harus mempertanggungjawabkn tugasnya kepada masyarakat, yang salah satu wujudnya adalah dengan menyampaikan laporan keuangan publikasi. Dengan adanya Kebijakan Akuntansi yang dikeluarkan Bank Indonesia, Bank Indonesia mampu menerepkannya sesuai dengan kebijakan dan ketentuan yang berlaku.

\section{TINJAUAN PUSTAKA}

Sistem Akuntansi Bank Indonesia. Sistem Akuntansi Bank Indonesia diatur dalam Peraturan yang dikeluarkan oleh Gubernur BI, dalam PDG No.1/12/PDG/1999 mengenai Sistem Akuntansi BI. Dan Kebijakan Akuntansi yang diterapakan BI atau KAKBI diatur dalam Pedoman Akuntansi Keuangan BI. PAKBI disususn dengan berdasarkan kepada Standar Akuntansi Keuangan, International Accounting Standard, Peraturan Intern BI, dan praktek-praketek diikuti oleh Bank Sentral yang ada di negara lain, dan juga keputusan antara BI, Badan Pemeriksa Keuangan RI dengan Dewan Standar Akuntansi Keuangan - Ikatan Akuntan Indonesia. Supaya bisa sejalan dengan perkembangan, terakhir dibuat SE No.5/47/INTERN 31 Oktober 2003 mengenai adanya perubahan ketiga atas SE BI No.4/58/INTERN 31 Desember 2002 yang membahas tentang PAKBI. Sesuai dengan Peraturan Dewan Gubernur (PDG) dimaksud, sistem akuntansi Bank Indonesia meliputi prinsip-prinsip, kebijakan, hubungan organisasional, prosedur, dan hubungan antarprosedur yang dirancang untuk mencatat transaksi keuangan, mengendalikan kegiatan operasional dan sumber daya Bank Indonesia, serta menyajikan informasi keuangan dalam rangka perencanaan, pengambilan keputusan, dan pelaporan. Berdasarkan pengertian tersebut ada 
beberapa aspek-aspek yang ada di sistem akuntansi BI diantaranya : (1) Pedoman Akuntansi Keuangan Bank Indonesia (PAKBI); (2) Buku Pedoman Sistematika Rekening (BPSR); petunjuk teknis otomasi sistem akunting yang terdiri (3) Bank Indonesia Aplikasi Sistem Akunting (BIASA); (4) Bank Indonesia Aplikasi Nostro Gabungan (BIANG); (5) Bank Indonesia Sistem Anggaran (BISA); (6) dan Bank Indonesia Data Akuntansi dan Keuangan (BIDAK); (7) dan telah disempurnakan dan diintegrasikan menjadi Sentralisasi Otomasi Sistem Akunting (SOSA).

Laporan Keuangan Bank Indonesia. Laporan Keuangan Bank Indonesia diatur dan disusun sesuai yang ada diperaturan dalam SE BI tanggal 31 Desember 2002 No.4/57/INTERN mengenai perubahan kedua atas SE BI tanggal 28 Desember 1999 No.1/27/INTERN yang membahas tentang Laporan Keuangan BI. Sesuai yang terdapat dalam UU No.23 Tahun 1999 mengenai BI sebagaimana yang telah diubah dengan UU No.3 Tahun 2004, laporan keuangan tahunan BI yang telah diaudit harus dipublikasikan di media massa. Komponen Laporan Keuangan BI terdiri dari : (1) Posisi Keuangan; (2) Surplus Defisit ; (3) Arus Kas; dan (4) Perubahan Posisi Modal. Laporan Keuangan BI tersebut disusun atas dasar akrual dengan konsep nilai historis, kecuali untuk akun tertentu yang berdasarkan pengukuran sebagaimana dijelaskan dalam kebijakan akuntansi.

Kerangka Dasar Laporan Keuangan Bank Indonesia. Kerangka Dasar Laporan Keuangan BI diatur dalam Prinsip Dasar Penyusunan dan Penyajian Laporan Keuangan yang berdasarkan dengan Peraturan Dewan Gubernur BI (PDGBI) tanggal 04 Mei 2012 No.14/10/PDG/2012 yang membahas tentang Kerangka Dasar Penyusunan Kebijakan Akuntansi Keuangan BI (KDPKAK-BI). Prinsip Dasar ini dibuat untuk sebagai acuan bagi :

1. Komite penyusun KAKBI.

2. Manajemen BI, dalam mengatasi masalah dalam akuntansi keuangan yang belum sesuai dengan pernyataan KAKBI.

3. Pemeriksa laporan keuangan BI, dalam memberikan opini atau pendapat dimana laporan keuangan BI telah disusun berdasarkan dengan pernyataan KAKBI atau tidak.

4. Para pengguna laporan keuangan BI, dalam menafsirkan informasi yang disajikan dalam laporan keuangan BI yang disusun harus sesuai dengan pernyataan KAKBI.

\section{METODE DAN TEKNIK PENERAPAN IPTEKS}

\subsection{Metode Penerapan Ipteks}

Metode ipteks yang diterapkan adalah Sistem Pelaporan Akuntansi yang sesuai dengan Kebijakan Akuntansi Bank Indonesia (KAKBI) mendasarkan Peraturan Dewan Gubernur Bank Indonesia (PDBGI).

\subsection{Teknik Penerapan Ipteks}

Teknik iptes yang diterapkan adalah dengan mengikuti aspek-aspek yang dikeluarkan oleh Bank Indonesia yakni : (1) Pedoman Akuntansi Keuangan Bank Indonesia (PAKBI); (2) Buku Pedoman Sistematika Rekening (BPSR); (3) petunjuk teknis otomasi sistem akunting yang terdiri Bank Indonesia Aplikasi Sistem Akunting (BIASA); (4) Bank Indonesia Aplikasi Nostro Gabungan (BIANG); (5) Bank Indonesia Sistem Anggaran (BISA); (6) dan Bank Indonesia Data Akuntansi dan Keuangan (BIDAK); (7) dan telah disempurnakan dan diintegrasikan menjadi Sentralisasi Otomasi Sistem Akunting (SOSA).

\section{PEMBAHASAN}

\subsection{Gambaran Objek Penerapan Ipteks}

Bank Indonesia adalah Bank Sentral yang ada di Republik Indonesia. Selain memiliki nama bank sentral, bank ini juga memiliki nama lain yaitu De Javasche Bank. Sekitaran satu abad kemudai kira-kira pada tahun 1953, De Javasche diganti menjadi Bank Indonesia. BI mempunyai tiga fungsi utama yakni di bidang perbankan, monter, dan sistem pembayaran. 
Selain fungsi tersebut BI diberikan juga wewenang untuk melaksanakan fungsi bank komersial. Lima belas tahun kemudian Pemerintah mengeluarkan UU Bank Sentral yang membahas tentang tugas dan kedudukan BI. UU ini dibuat sebagai pembeda kepada bankbank lain yang melaksanakan fungsi komersial. Setelah UU diterbitkan, BI memiliki tambahan tugas dimanan BI membantu pemerintah didalam mewujudkan kesejahteraan rakyat. Sesuai yang terkandung dalam UU No.23 Tahun 1999 BI dalam mengahadapi dan memasuki era baru dalam sejarah Bank Sentral independen yang mempunyai satu tujuan tunggal yaitu untuk mencapai dan memelihara kestabilan nilai rupiah. Seabagai salah satu fungsi dalam mengawai perbankan yang kemudian di alihkan kepada OJK, fungsi tersebut tetap berlaku namun lebih difokuskan pada aspek makroprudensial sistem perbankan secara makro. BI juga adalah salah satu Lembaga yang memiliki hak untuk mengedarkan uang di Indonesia.

Kebijakan Akuntansi Bank Indonesia. Di dalam Kebijakan Akuntansi BI (KAKBI) John Dalton dan Chris Ford4, dalam naskahnya "General Purpose Financial Statements for Central Banks" mengatakan bahwa 35 standar dari International Accounting Standard (IAS) mempunyai potensi untuk dapat diterapkan di organisasi perbankan termasuk Bank Indonesia (BI), tetapi yang paling relevan untuk bank adalah IAS 1 (Presentation of Financial Statements), IAS 30 (Disclosure in the Financial Statements of Banks and Similar Financial Institutions), IAS 32 (Financial Instruments: Disclosure and Presentation), dan IAS 39 (Financial Instruments: Recognition and Measurement). Dengan kaitannya dengan Bank Indonesia (BI), mereka antara lain mengatakan bahwa "Ketaatan terhadap standar akuntansi dan pengungkapan yang berlaku, seperti IAS, merupakan prasyarat penerapan Transparansi dan Good Governance". Oleh karena itu, sedapat mungkin dalam menetapkan kebijakan akuntansinya Bank Sentral hendaknya tetap mengacu kepada IAS. Standar Pelaporan BI dan standar akuntansi bank komersial tidak sama meskipun ada beberapa kemiripan. Hal ini dikarenakan tujuan dan tugas BI bukanlah diutamakan untuk mendapatkan keuntungan sebagaimana tujuan bank komersial, melainkan lebih untuk melaksanakan pengendalian moneter. Uraian mengenai sistem akuntansi Bank Sentral ini berdasarkan yang diterbitkan oleh International Monetary Fund (IMF) yang merupakan rangkuman dari praktekpraktek akuntansi di Bank Sentral-Bank Sentral, yang diperoleh melalui work shop antar Bank Sentral di seluruh dunia yang diselenggarakan secara tahunan oleh IMF, serta dari hasil studi komparasi penulis baik melalui bacaan maupun kunjungan di beberapa Bank Sentral.

\subsection{Pembahasan}

Sistem Pelaporan Akuntansi hendaknya mengikuti aspek-aspek dibawah ini agar Pelaporan Akuntansi sesuai dengan Sistem Akuntansi :

1. Pedoman Akuntansi Keuangan Bank Indonesia (PAKBI). Pencatatan transaksi keuangan Bank Indonesia mengacu pada Pedoman Akuntansi Keuangan Bank Indonesia (PAKBI), suatu pedoman yang merupakan himpunan prinsip dan teknis akuntansi yang mengatur metode pencatatan, penilaian, pengakuan, pelaporan, dan pengungkapan transaksitransaksi keuangan yang terjadi di Bank Indonesia, yang terdiri dari standar akuntansi Aktiva, standar akuntansi Kewajiban, standar akuntansi Modal, standar akuntansi Pendapatan, dan standar akuntansi Biaya. PAKBI pada awalnya merupakan kependekan dari Prinsip Akuntansi Keuangan Bank Indonesia yang disusun dan dimaksudkan untuk digunakan sendiri oleh Bank Indonesia. Pada tahun 1995 pernah dilakukan penjajagan dengan Ikatan Akuntan Indonesia (IAI) mengenai kemungkinan PAKBI ini dijadikan sebagai salah satu standar akuntansi keuangan dan menjadi bagian dari StandarAkuntansi Keuangan (SAK), dengan sebutan Standar Akuntansi Keuangan Bank Indonesia (SAKBI). Namun, berdasarkan penjelasan dari Dewan Standar Akuntansi Keuangan Ikatan Akuntan Indonesia (DSAK - IAI), kata standar digunakan untuk suatu acuan yang dipakai oleh lebih dari satu entitas. Dengan demikian, PAKBI yang hanya digunakan oleh 
Bank Indonesia tidak tepat apabila dijadikan sebagai suatu standar akuntansi keuangan. DSAK mengusulkan untuk memakai kata pedoman sehingga namanya menjadi Pedoman Akuntansi Keuangan Bank Indonesia (PAKBI).

2. Buku Pedoman Sistematika Rekening (BPSR). Sistem rekening Bank Indonesia merupakan struktur dan klasifikasi rekening-rekening yang berlaku di Bank Indonesia berdasarkan sifat dan fungsinya. Hal ini dimaksudkan agar setiap rekening dapat secara jelas mencerminkan hak dan kewajiban Bank Indonesia dalam rangka melaksanakan fungsinya, baik sebagai Otoritas Moneter (Bank Sentral) maupun sebagai suatu badan usaha. Saat ini sistem rek.ening Bank Indonesia diatur dalam Buku Pedoman Sistematika Rekening (BPSR). Buku ini merupakan penyempurnaan dari Buku Pedoman Sistematika Neraca (BPSN) dan berfungsi untuk memberikan penjelasan secara singkat dan jelas tentang struktur, nama, dan sandi rekening yang digunakan di Bank Indonesia sehingga diperoleh pengertian dan pemahaman yang seragam; memberikan penjelasan secara singkat dan jelas tentang transaksi yang dicatat dalam masing masing rekening; memberikan penjelasan secara singkat dan jelas mengenai batasan wewenang dan tanggung jawab satuan kerja-satuan kerja di Bank Indonesia maupun pihak lain dalam kaitannya dengan pembukaan, penutupan, dan pengawasan rekening.

3. Bank Indonesia Aplikasi Sistem Akunting (BIASA). BIASA yaitu sistem yang digunakan untuk mencatat dan memproses transaksitransaksi keuangan dalam mata uang Rupiah, kecuali transaksi penerimaan dan pengeluaran. BIASA adalah sistem aplikasi yang digunakan di kantor pusat, sedangkan OSA digunakan di Kantor Bank Indonesia (kantor cabang).

4. Bank Indonesia Aplikasi Nostro Gabungan (BIANG). BIANG yaitu sistem yang digunakan yaitu sistem yang digunakan untuk mencatat dan memproses transaksitransaksi keuangan dalam mata uang asing. BIANG hanya digunakan di kantor pusat Bank Indonesia.

5. Bank Indonesia Sistem Anggaran (BISA). BISA yaitu sistem yang digunakan untuk menyusun anggaran (rencana keuangan), dan mencatat serta memproses transaksitransaksi penerimaan dan pengeluaran. BISA digunakan di seluruh kantor Bank Indonesia baik pusat maupun kantor perwakilan.

6. Bank Indonesia Data Akuntansi dan Keuangan (BIDAK). BIDAK yang merupakan sistem untuk mengkonsolidasi data akuntansi (transaksi) dari seluruh sistem aplikasi akunting yang ada. BIDAK juga merupakan sistem yang digunakan untuk menyusun laporan keuangan konsolidasi Bank Indonesia.

7. Sentralisasi Otomasi Sistem Akunting (SOSA). Penyempurnaan sistem akuntansi yang ada di BI masih terus dilakukan, lebih-lebih lagi dengan diundangkannya UU RI No.23 Tahun 1999 tentang Bank Indonesia sebagaimana telah diubah dengan UU No.3 Tahun 2004, yang menuntut BI untuk lebih transparan dan accountable di dalam menjalankan tugas dan fungsinya. Maka Bank Indonesia telah menggulirkan program transformasi dalam berbagai bidang, di antaranya dalam planning, budgeting, dan performance measurement (P, B \& PM). Sebagai konsekuensi dari transformasi tersebut diperlukan pula transformasi/penyempurnaan di dalam sistem yang terkait, yaitu sistem accounting dan budgeting, atau dalam pengertian luasnya adalah sistem keuangan. Hal ini sejalan dengan blue print Manajemen Keuangan Bank Indonesia (MKBI), yang telah disusun pada tahun 2000 dengan bantuan konsultan PT. Ernst \& Young, untuk menciptakan sistem keuangan Bank Indonesia yang lebih komprehensif, terotomasi, dan terintegrasi dalam upaya mewujudkan good governance. Penyempurnaan tersebut dilakukan dengan mengintegrasikan seluruh sistem-sistem yang ada menjadi satu sistem yang disebut Sentralisasi Otomasi Sistem Akunting Bank Indonesia(SOSA). SOSA memiliki karakteristik yakni : 
- Suatu sistem keuangan yang terintegrasi dapat menunjang fungsi planning, actuating, reporting, dan monitoring terhadap kegiatan keuangan intern Bank Indonesia.

- Suatu sistem yang dapat memproses transaksi keuangan untuk menghasilkan data yang akurat, lengkap, dan tepat waktu, yang pada akhirnya dapat dimanfaatkan oleh sistem data warehouse Bank Indonesia untuk menunjang kebutuhan sistem informasi core function suatu Bank Sentral.

- Suatu sistem yang dapat menghasilkan informasi/laporan yang dapat digunakan untuk kebutuhan deteksi dini (early warning) dan analisis dalam rangka menunjang fungsi pengendalian keuangan (management control) dan manajemen resiko yang pada akhirnya menunjang proses pengambilan keputusan yang berbasis informasi (information-based decision making).

- Suatu sistem yang terintegrasi meliputi General Ledger System dan Subsidiary Ledger, yang menunjang kebutuhan fungsi financial accounting dan management accounting.

- Suatu sistem yang didasarkan pada proses dan prosedur akunting serta kaidah-kaidah kebijakan akuntansi yang diterima umum (best practice), dan praktek-praktek akuntansi di bank-Bank Sentral.

\section{KESIMPULAN DAN SARAN}

\subsection{Kesimpulan}

Sistem Pelaporan Akuntansi Bank Indonesia (BI) mengikuti praktek-praktek akuntansi sesuai dengan Kebijakan Akuntansi Bank Indonesia (KBBI) dan juga mendasarkan pada Peraturan Dewan Gubernur Bank Indonesia (PDGBI) yang sesuai dengan aspek-aspek yang diterapkan.

\subsection{Saran}

Perlunya adanya upaya untuk terus meningkatkan transparansi dan akuntabilitas Bank Indonesia kepada publik supaya kualitas informasi Sistem Pelaporan Akuntansi BI yang disajikan kepada stakeholder akan selalu dijaga baik dari segi keandalan, keakuratan, maupun dari segi ketepatan waktunya sesuai dengan sistem dan kebijakan di keluarkan oleh Bank Indonesia.

\section{DAFTAR PUSTAKA}

Komite Penyusunan KAKBI. 2012. Kebijakan Akuntansi Keuangan Bank Indonesia (KAKBI). Jakarta: Bank Indonesia.

Ikatan Akuntan Indonesia (1999), "Standar Akuntansi Keuangan.

Peraturan Dewan Gubernur BI (PDG) No.1/12/PDG/1999 tentang Sistem Akunting Bank Indonesia.

SE tanggal 31 Oktober 2003 No.5/47/INTERN tentang Perubahan ketiga atas SE BI tanggal 31 Desember 2002 No.4/58/INTERN mengenai Pedoman Akuntansi Keuangan Bank Indonesia (PAKBI).

International Monetary Fund (1997), “Accounting For Foreign Exchange In Central Bank Operation".

International Monetary Fund (1996), "Central Bank Accounting Workshop Collection".

J. B. Heckert (1983), "Controllership : Tugas Akuntan Manajemen", Penerbit Erlangga Jakarta.

Nugroho Widjajanto (2001), "Sistem Informasi Akuntansi”, Lembaga Penerbit Fakultas Ekonomi Universitas Indonesia.

S. Munawir (2002), “Akuntansi Keuangan dan Manajemen”, BPFE Yogyakarta.

Peraturan Dewan Gubernur BI No.14/10/PDG/2012.

Peraturan UU RI No.23 Tahun 1999. 